\title{
Multi-decadal temperature changes off Iberia over the last two deglaciations and interglacials and their connection with the polar climate
}

\author{
Belen Martrat ${ }^{1,2}$, P.C. Tzedakis ${ }^{3}$, V. Margari ${ }^{3}$, L.C. Skinner ${ }^{2}$, D.A. Hodell ${ }^{2}$ and J.O. Grimalt ${ }^{1}$
}

\begin{abstract}
The lberian margin provides climatic and environmental sediment records with multi-decadal resolution over the last two deglaciations and interglacials. These records allow us to identify climatic structures and discuss interhemispherical connections.
\end{abstract}

More than a decade has passed since it was verified that major temperature changes in Atlantic surface and deep waters at the Mediterranean latitudes were closely connected with Greenlandic and Antarctic climatic variability (Shackleton et al. 2000). Since then, deep sea sediments retrieved at the lberian continental margin (e.g. Martrat et al. 2007; Hodell et al. 2013; Margari et al. 2010,2014 ) have been adding further clues, showing that episodic abrupt change is a fundamental aspect of the Earth's climate. Anomalies were observed to take place rapidly enough to be noticed in the time frame of a regular human life and persist long enough to cause substantial disruptions in natural, and potentially socioeconomic, systems. Hence, far from only being of academic interest, the long-term management of our livelihoods now require pushing the data to the limits and focusing on fine-scale details (Shackleton, 2006).

A recent study of site ODP-976 (Martrat et al. 2014) has provided such detailed records over the present interglacial (Holocene, initiated at 11.7 ka before present), the Last
Interglacial (LIG, onset approximately at 129 $\mathrm{ka})$, and the respective deglaciations. The marine records obtained for the penultimate deglaciation and the LIG onset are particularly relevant, given the difficulties in obtaining an undisturbed ice core record from Greenland for this interval (NEEM community members, 2013). In this regard, the fact that the bipolar effect is well illustrated at the lberian margin (Martrat et al. 2007; Margari et al. 2010) provides us with a robust basis for a Holocene-to-LIG comparison. Alkenone measurements enabled reconstruction of a sea surface temperature (SST) profile with a temporal resolution of 60 to 90 years and an associated uncertainty lower than $0.5^{\circ} \mathrm{C}$. Events and transitions described and published before on the basis multi-proxy evidence (isotopes, vegetation, ice-rafted debris, etc.) from other Iberian sites (ODP-977, MD95-2043, MD95-2042, and MD01-2444) were essential for establishing hypotheses regarding long-distance climatic connections. Chronological uncertainties are commonly less than four centuries for the Holocene, but significantly higher - from two to even six millennia - for the LIG, when astronomical calibration of time scales is used as the main reference. In the paleotemperature record, three types of structures relevant to inter-hemispherical connections stand out: "Ws", "saddles", and a "cooling trend". We discuss each of these in turn below.

\section{The "Ws": Heinrich stadials less static than previously apparent} Heinrich $(\mathrm{H})$ events are identified in marine sediments of the mid-latitude North Atlantic as layers with a concentration of ice-rafted debris and scarcity of foraminifera. As a first-order description, $\mathrm{H}$ events are flat cold anomalies between some of the Dansgaard-Oeschger warm interstadials, which modelers simulate by putting freshwater perturbations or icebergs into Arctic latitudes (e.g. Jongma et al. 2013). However, increasingly detailed SST reconstructions at Mediterranean latitudes, specifically from sites ODP-976 and MD01-2444, suggest that cold stadial periods associated with $\mathrm{H} 11$ and $\mathrm{H} 1$ were anything but static. A sharp warming occurred halfway their progression, causing a characteristic "W" shape in
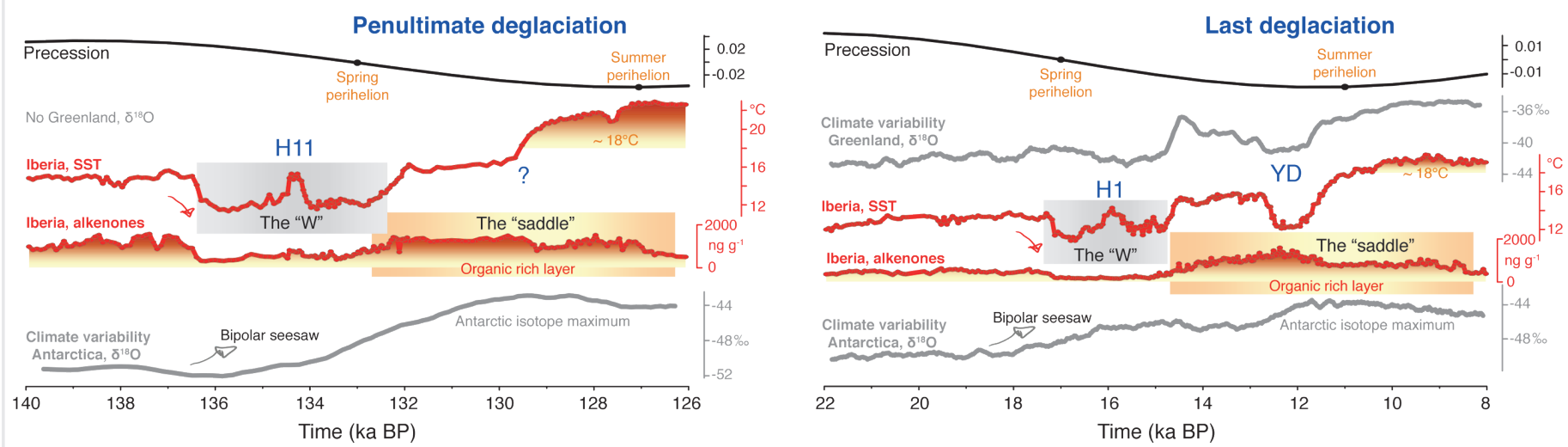

Figure 1: The penultimate (left) and last (right) deglaciations in Greenland, off Iberia, and Antarctica. From top to bottom: the precessional oscillation; climate variability traced by the Greenland NGRIP ice core $\left(75^{\circ} \mathrm{N}\right)$; alkenone-derived sea surface temperatures (SST) and total alkenone amount from marine sediment core ODP-976 (36 $\mathrm{N}$ ); and climate variability registered in the EPICA Dronning Maud Land ice core $\left(75^{\circ} \mathrm{S}\right)$. Two main structures relevant to inter-hemispherical connections stand out: the "Ws" and the "saddles". 
the SST records during these episodes (Fig 1). Long-term vegetation patterns in the Mediterranean show that extreme dry and cold episodes took place during periods around perihelion passage in Northern Hemisphere (NH) spring equinox (Magri and Tzedakis, 2000). The cold spells observed within the stadials associated with $\mathrm{H} 11$ and $\mathrm{H} 1$ are placed around this orbital signature, i.e., ca $133 \mathrm{ka}$ and $17 \mathrm{ka}$, respectively, including the abrupt warming events within them (up to $4^{\circ} \mathrm{C}$ in less than eight centuries; Fig. 1).

Skinner and Elderfield (2007) suggest that the occurrence of sharp warming events at the centre of the stadials associated with $\mathrm{H}$ events indicates the potential energy storage of the deep North Atlantic. The warmings appear linked to the culmination of a large reduction in the Atlantic meridional overturning circulation, ice surge phases with moderate rise in sea level, and possible sub-surface warming feedbacks (Flückiger et al. 2006). These multi-decadal scale oscillations within $\mathrm{H}$ events may have played an active role in the progressive glacial-to-interglacial re-activation of convective deep-water formation in the North Atlantic, adding a new element to the bipolar-seesaw between the Northern and the Southern Hemispheres.

\section{The "saddles" as a reference for deglacial processes}

Deposition of organic rich layers, showning up as alkenone accumulation maxima, characterize the later part of the last two deglaciations when perihelion moves from alignment with the $\mathrm{NH}$ spring equinox to the summer solstice (from 132 to 126 ka and from 15 to 9 ka, respectively; Fig. 1). These layers are not comparable with the sapropels known from the eastern Mediterranean, neither in magnitude, nor timing, or mode of formation. They are features unique to the western Mediterranean. Their deposition histories show different maxima, the youngest ones separated by a significant "saddle" (Rogerson et al. 2008). Alkenone accumulation compares well between the last and penultimate deglaciations, but the derived SSTs differ (Fig. 1). Essentially, a cooling is recorded during the last deglaciation, around $12 \mathrm{ka}$ (during the Younger Dryas; YD), while there is no analogous cooling over the penultimate deglaciation around $130 \mathrm{ka}$. This difference proves dissimilarities in the developments of the last two deglaciations. Surface and bottom water temperature records from off Iberia reflect the temperature changes over Greenland and Antarctica, respectively. They can thus be used to study temporal relationships between the Iberian and the polar regions. Maxima in the Antarctic water isotopic record (MassonDelmotte et al. 2011) suggest mild climate in Antarctica during the deposition of both deglacial organic rich layers in the western Mediterranean. This is interesting in that both deglaciations are otherwise remarkably dissimilar in Antarctica, pointing to different configurations of ice sheets and varying strengths in thermohaline circulation during the last two deglaciations, with a dissimilar impact on SSTs across both hemispheres.

\section{A long-term "cooling trend" and bipolar-seesaw variability}

Some specific events during the interglacial progression capture our attention, though a trend towards colder climatic conditions dominates the observed SST variability quite prominently (Fig. 2). Interglacial multi-decadal scale events are superimposed upon this long-term trend towards colder SSTs. The ending of organic rich layer deposition in the western Mediterranean marks the onset of temperate Mediterranean conditions with relatively mild winters and winter rainfall, compared with the extreme seasonality of precipitation that characterized the interglacial onset. In Iberia, temperate intervals commence after the $8.2 \mathrm{ka}$-event and are over at $5.3 \mathrm{ka}$ for the Holocene; for the LIG, they commence after $125 \mathrm{ka}$ and are over at $121 \mathrm{ka}$ (Fig. 2). During the $\mathrm{LIG}$, the cooling trend is steeper $\left(-0.4^{\circ} \mathrm{C} /\right.$ ka from $122 \mathrm{ka}$ to $116 \mathrm{ka}$ ) than during the Holocene $\left(-0.1^{\circ} \mathrm{C} / \mathrm{ka}\right.$ from $6 \mathrm{ka}$ to $\left.0.7 \mathrm{ka}\right)$. Trends simulated by an ensemble of climate models are qualitatively consistent with these Iberian cooling trends (Bakker et al., 2014). A cold spell of around eight centuries at 2.8 ka during the Holocene is possibly mimicked during the LIG at 118 ka by a fall of around $1^{\circ} \mathrm{C}$ within a millennium. These events lead interglacial SST to stabilize at around $18^{\circ} \mathrm{C}$, i.e. at a value comparable to the present average annual in the western Mediterranean. The glacial inception at 115 ka commenced after perihelion passage in the $\mathrm{NH}$ winter solstice and culminated with a drop of at least $2^{\circ} \mathrm{C}$ in a few millennia, placed in the Iberian cores at $111 \mathrm{ka}$, around perihelion passage in the $\mathrm{NH}$ spring equinox. The end of the LIG occurred late in the ice-sheet growth cycle and involved major re-activation of the bipolar-seesaw. The Little Ice Age (0.7 ka), which had strong impacts on European societies, also occurred after the latest perihelion passage in the $\mathrm{NH}$ winter solstice and may be an example of a glacial pre-inception event following an interglacial.

\section{DATA}

Data from ODP site 976 are available at http://doi. pangaea.de

\section{AFFILIATIONS}

'Department of Environmental Chemistry, Institute of Environmental Assessment and Water Research (IDAEA-CSIC), Barcelona, Spain

${ }^{2}$ Department of Earth Sciences, University of Cambridge, UK

${ }^{3}$ Department of Geography, University College London, UK

\section{CONTACT}

Belen Martrat: belen.martrat@idaea.csic.es

\section{REFERENCES}

Bakker P et al. (2014) Quat Sci Rev 99: 224-243

Flückiger J et al. (2006) Paleoceanography 21, doi:10.1029/2005PA001204

Jongma Jl et al. (2013) Clim Dyn 40, 1373-1385 Hodell DA et al (2013) Paleoceanography 128, 185-199

Margari V et al. (2010) Nat Geosci 3, 127-131

Margari V et al. (2014) Geology 42: 183-186 Magri D, Tzedakis PC (2000) Quat Int 73-74: 69-78 Martrat B et al. (2007) Science 317: 502-507

Martrat B et al. (2014) Quat Sci Rev 99: 122-134

Masson-Delmotte $V$ et al. (2011) Clim Past 7: 397-423 NEEM community members (2013) Nature 493: 489-494 Rogerson M. et al. (2008) Geochem Geophys Geosyst 9, doi:10.1029/2007GC001936

Shackleton NJ et al. (2000) Paleoceanography 15: 565-569

Shackleton NJ (2006) Quat Sci Rev 25: 3458-3462

Skinner LC, Elderfield H (2007) Paleoceanography 22, doi:10.1029/2006PA001338
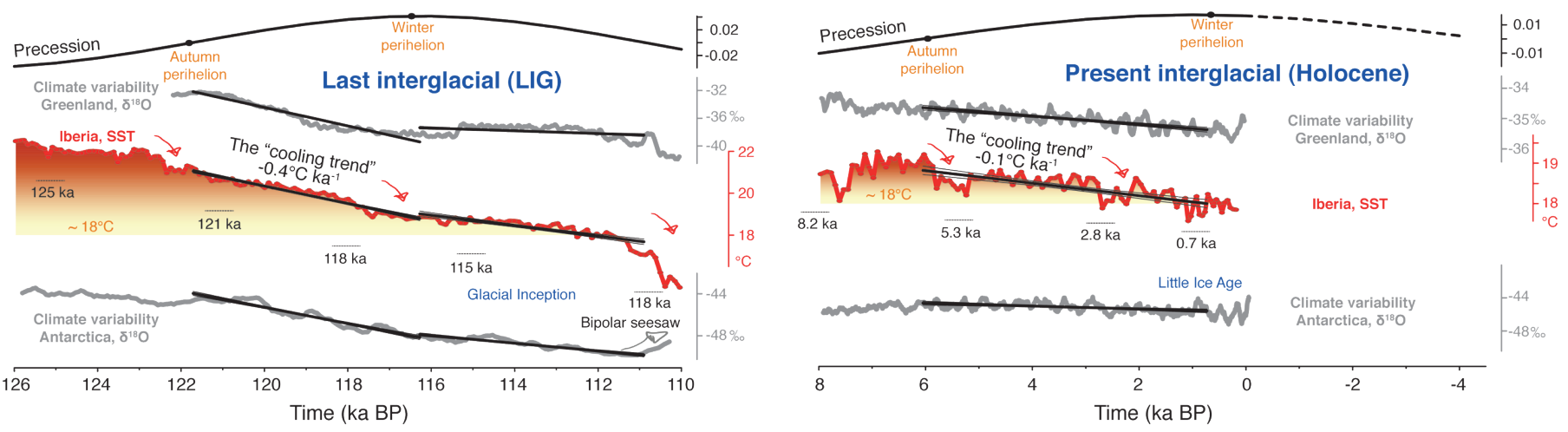

Figure 2: The last (left) and present (right) interglacials in Greenland, off Iberia and Antarctica. The descriptions of the individual curves are the same as for Figure 1. The distinctive feature is the "cooling trend", calculated between perihelion passage in the NH autumn equinox and winter solstice - and the bipolar-seesaw variability that ensues. 